\title{
Immune Modulation in Patient with Varicella Zoster Virus Treated with Phototherapy and Chemotherapy
}

\author{
Zainab A.M Alqassemi* \\ Department of Biology, Collage of Sciences, \\ University of AL-Qadisiya, Iraq \\ Zeinab_alqassemi@yahoo.com
}

\author{
Ziad M.F Alkhozai ** \\ Department of Medical Biotechnology / College \\ of Biotechnology, Iraq \\ ziad_alkhozai@yahoo.com
}

\begin{abstract}
Herpes zoster (HZ; shingles) a reactivation of the latent varicella zoster virus ,the most complication of $H Z$ is postherptic neuralgia PHN. This study was carried out to evaluate the effects of $n b-U V B$ (narrow band-UVB), on T-regulatory cells through gene expression of transcription factors: FOXP3, NFAT,API and IL-6 cytokine. The study included three groups: T1 group treated by phototherapy and antiviral, T2 group received chemotherapy (antiviral only), and control group. Obtained results of FOXP3 showed significant elevation in gene expression for both $T 1$ and $T 2$ group in comparison to control group (1.91 1.25$)$. In case of NFAT, the results revealed significant changes between the groups and control group (3.002 \pm 0.86$)$. Also the gene expression of AP-1 levels showed mild changes in T2 group, in other hand the results were highly significant between $T 1$ and control group (1.88 1.25). Those finding were supported by the findings of IL-6 levels, which showed highly significant increment in T2 group at the end of treatment $(87.8 \pm 24.09 \mathrm{pg} / \mathrm{ml})$, in comparison to the period before treatment $(77.43 \pm 17.3 \mathrm{pg} / \mathrm{ml})$, while in control group $(59.6 \pm 1.21 \mathrm{pg} / \mathrm{ml})$. For $\mathrm{T1}$ group the data showed significant reduction among the sessions $(73.13 \pm 23.7 \mathrm{pg} / \mathrm{ml})$ before sessions and reaching the normal limits $(60.33 \pm 13.04 \mathrm{pg} / \mathrm{ml})$ at the end of sessions, which was $(59.6 \pm 1.21 \mathrm{pg} / \mathrm{ml})$. The results of this study also showed the improvement in the verbal rat score VRS (100\% cure, pain relief) at T1 group, while T2 group showed (80\% pain relief). The overall results indicate that the using of $n b-U V B$ for treatment may lead to modulation of response of $T$ - regulatory cells which resulted in full recovery of VZV infection.
\end{abstract}

Keywords: T-regulatory cells, FOXP3, NFAT, AP-1, IL-6.

\section{INTRODUCTION}

VZV is an exclusively human, high neurotropic Alphaherpesvirus of the Varicellovirus genus, VZV causes two important related infections, primary infection causes Varicella (chicken pox), and latent infection herpes zoster HZ (shingles) (Avein et al.,2013). HZ results as activation of VZV from nerves were it was latent after infection with chicken pox (Gliden, 2011). The activation of virus could be due to reduction of VZV-specific T-cells (CD4+T lymphocytes), that keep the virus latent and prevent the reactivation occur back with aging or in the causes of immune compromised, VZV high pathogensis virus during the infection the antigen of VZV stimulate T- lymphocytes that lead to express many of immune regulation genes which involve many transcription factors functionally essential to management and initiation of immune response (Younk et al., 2013). It includes NFAT (nuclear factor activated transcription factor), and AP-1 (activated protein transcription factor), NFAT which is consider a key regulator of T cells activation and energy (Famando, 2005).

NFAT transcription factor family consist of five member: NFAT1, NFAT2, NFAT3, NFAT4, and NFAT5 that expressed in immune system cells like T and B cells, natural killer cell (NK), and also in non- immune system and tissues like heart muscle, skeleton muscle, and neurons (Nagamoto \&Combs,2010). NFAT form cooperative complex with AP-1 family which belong to C-fos, C-jun, ATF, families. AP-1 in turn control a number of cellular process including differentiation, proliferation, apoptosis, and it is regulating gene expression in response to various stimuli included cytokines, stress, bacterial and virus infection (Karolin et al.,2014). NFAT + AP-1 complex responsible in the activation of $\mathrm{T}$ cells (CD4 and CD8 $\mathrm{T}$ cell), $\mathrm{T}$ helper cell CD4 induced the production of pro- inflammatory cytokines which have role in acute phase of $\mathrm{HZ}$ infection such as IL2, IL-6, IL-12 and INF $\alpha, \gamma$ (Rishi et al.,2012). CD8 cell play an important role in elimination of virus in addition to CD4 which have role in both latent and activated form of virus (Van et al., 2012). Where these cells can recognize the mediated proteins that express by VZV during it latency in 
ganglion nerves for that cells mediated immunity (CMI) can limit the replication and spread of VZV with nerves and not to reactivation (Michael,2009).

There is association between the magnitude of CMI and cytokines production in limiting the severity of $\mathrm{HZ}$ in one hand, on the other hand the extent response and production of pro-inflammatory cytokines for non-infected cells and tissues lead to harmful consequences to the host, so there is need of T- regulatory cells which can be recognized from the cluster of differentiation on its surfaces include (CD4+CD25+FOXP3) (Sakaguchi et al.,2009). The importance of T- regulatory cell lies in the control of the peripheral tolerance, preventing auto immune disease and limits the inflammatory immune response to be chronic. FOXP3 (fork head protein) produced by gene foxp3 its bind to specific region on DNA and control on many of gene expression, FOXP3 have crucial role in development and function of T- regulatory cell (Aaron et al.,2014). Both of FOXP3 and T- regulatory cells have an important role of VZV infection and many other virus like hepatitis, Epstein bar virus and herpes virus, through regulating the excessive inflammatory response and protect the non-infected cells and tissues from destruction (Givennikoy\&Karin,2010). Where FOXP3 control the activation of T-lymphocytes and their production of pro-inflammatory cytokines by interaction with other transcription factors like NFAT, NF-KB and AP-1 which cause to decrease the inflammation, FOXP3 also express many of anti-inflammatory cytokines like IL-10, IL-35 which causes inhibition the proinflammatory cytokines.

One of the ways that induced the T- regulatory cell expression is by exposure to nb-UVB phototherapy which includes a range of radiation spectrum ultraviolet nearly $311 \mathrm{~nm}$ where its less than $1 \%$ from waves of sun rays (Kaplan et al.,2006). Nb-UVB use for remediation many of skin disease like skin infection, psoriasis, vitilago, eczema, fungi, itching and inflammation of nervous and skin (Haykal\&Desgroseilliers,2006). nb-UVB have many mechanisms in regulation of immune response : induced the expression of T- regulatory cell and FOXP3, prevent the antigen presenting and apoptosis of leukocytes. Nb-UVB gives therapeutic results faster with less side effects such as skin sensitive, redness and erythematic, also it have wide positive effect in treatment. This work was aimed to determine the modulation of the gene expression of T- regulatory cells in patients with VZV treated by phototherapy and chemotherapy.

\section{MATERIAL AND MethodS}

\subsection{Patients Groups}

This study was done during December 2014 to April 2015. It was carried out on 115 individuals (70 patients was infected with $\mathrm{HZ}$ at acute stage, 20 patients was infected with PHN and 25 healthy apparently individuals as control group). The study was done in AL-Diwanya Teaching Hospital / Department of Dermatology. Patient's ages ranged from 7-80 years. The first visit of patients in the hospital in all most within 10 days of the development of symptoms of HZ rash, as reported by the physicians and patients, then they divided into two groups: T1 group (50 patients) who treated with phototherapy by NB-UVB cabin beside antiviral /acyclovir $800 \mathrm{gm}$ five times a day for 7 days. and T2 group (40 patients ) who received antiviral / acyclovir $800 \mathrm{gm}$ five time a day for 7 days with corticosteroid in severe pain cases, for both groups the VRS (variable rat score) was recorded in every visit to the hospital which determined by the dermatologist.

\subsection{Designing Phototherapy Sessions}

Sessions of phototherapy included (50) patients infected with HZ and PHN, Patients who had received treatment in Department of Dermatology in NB-UVB cabin, it is carried out on (35) men and (15) women with age range from 30-80 years. Every patients had a different degree of pain average between (0-4) point according to a variable rate score VRS, every point means a different degree of pain where (0) means no pain and (4) which means incredible pain, T1 group treated with NB-UVB (narrow band ultraviolet 311) for three times per week, exposed locally at infected part of body while the rest of body was covered by clothing, first session started with dose $30 \mathrm{mj} / \mathrm{cm}$ (40 second) and the dose was gradually increased by $10 \mathrm{mj} / \mathrm{cm}$ at every session until reach $180 \mathrm{jm} / \mathrm{cm}(2-3$ minutes $)$ as long as there is no adverse effect reported such as persisting erythematic ,burn and itching. Patients still get session until pain relief or for a maximum 18 sessions (Jalali et al.,2006).

\subsection{Collection of Samples}

Five $\mathrm{ml}$ of vinous blood were collected from studied group (one sample per week). $2 \mathrm{ml}$ of blood kept in (EDTA) tube as anticoagulant, and $3 \mathrm{ml}$ left in the room temperature at 30 minutes. Then serum 
was separated by centrifuge at the $4000 \mathrm{rpm}$ for 5 minutes. Both of the blood samples and sera stored at -20c in deep freeze unit (Lewis et al., 2006) until used for immunological and molecular assays

\subsection{Ethical Precautions}

This work was done in cooperation with Departments of Health Research at Ministry of Health / Iraq and with cooperation of dermatologist from Department of Dermatology / AL-Diwanyia Teaching Hospital, all patients and control individuals were consented formally to do this study.

\subsection{IL-6 Profile}

IL-6 was assayed by Elisa using kit according to manufacture (Ray Bio ${ }^{\circledR}$ the protein array pioneer company).

\subsection{Primer Design and Study}

Primers that used in this study were GAPDH (Glycerol Aldehyde-3-Phosphate Dehydrate Genies). Gene primers used as Housekeeping gene, FOXP3, NFAT and AP-1 genes. Primers used as target genes for gene expression. These primers were designed by using NCBI- Gene Bank data base and Primer 3 plus online. The primers used in quantification of gene expression using RT-qPCR techniques based SYBER Green DNA binding dye, and supplied by (Pioneer, Korea). As listed in (Table -1).

\subsection{Quantitative Reverse Transcription Real-Time PCR (RT-qPCR)}

Quantitative Reveres Transcription Real-Time PCR technique was performed for assessment of comparative quantification (gene expression analysis of FOXP3, NFAT \& AP-1). This technique was done according with the described method by (Wang \& Hardy). The following thermo cycler protocol in the following (Table -2):

\subsection{Data Analysis of qRT-PCR}

The results of data of qRT-PCR for target and housekeeping genes were analyzed by the relative quantification gene expression levels (fold change). Reference method that described by ( Radonic et al.,2004).

\subsection{Statistical Analysis}

Obtained data were statistically analyzed using the statistical package SPSS (Statistical Package for Social Sciences) version 10.0 for windows. The investigated parameters were presented in as mean \pm standard error (S.E.), and differences between means were assessed by ANOVA (analysis of variance), followed by LSD (least significant difference). The difference was considered significant when the probability $(P)$ value was $\leq 0.05(18)$.

\section{RESUlts}

\subsection{Distributions of Herpes Zoster Infection}

The results showed that infected men were higher than women for both $\mathrm{HZ}$ and PHN, about 67 men (74.44\%) and 23 women (25.55\%) as showed in the figure (1). Results also showed that the highest proportion of $\mathrm{HZ}$ infections within age group (41-60) by 39 (55.71\%) followed by age group $(\geq 60)$ by $16(22.85 \%)$ compared with the rest of groups which were the proportion of age group (1-20) are $6(8.57 \%)$ and age group (21-40) are $9(12.85 \%)$ as show in the figure (2). For PHN documented results showed that the highest proportion of cases were within the age group (> 60) by $11(65 \%)$ followed by age group (41-60) by 5 (25\%) and category (21-40) are $2(10 \%)$ and there are a lack in category (1-20) are (0\%) as showed in figure (3).

\subsection{Il-6 Profile}

Obtained data of IL-6 levels showed a significant increase $(P>0.05)$ in the levels of il-6 in T2 group (87.8 \pm 24$)$, compared to control (59.6), and T1 group (60.46 \pm 13.04$)$, who showed no significant change ( $>0.05$ ) in comparison to control group (59.6) as showed in the figure (4 and 5).

\subsection{FOXP3 Gene Expression}

The documented results showed a significant increment $(\mathrm{P}>0.05)$ in the gene expression of FOXP3 for T1 and T2 group compared to the control group (1.910 \pm 0.6846$)$, data recorded highly significant increment in T1 group (18.22 \pm 5.44$)$ at the end of the sessions in comparison to the stage before sessions $(10.5 \pm 2.5)$, while the data showed that in the T2 group there is no significant differences ( $\mathrm{P}$ 
$>0.05)$ between the end of treatment $(10.85 \pm 6.5672)$ and the stage before treatment $(14.5 \pm 10.6)$, Concluded data showed that the expression of FOXP3 at the end of treatment was higher in the T1 group than T2 group and control group as showed in table (4).

\subsection{NFAT Gene Expression}

The obtained results showed a significant change (P>0.05) compared to control (3.002 \pm 0.86$)$, in other hand there was no significant difference before starting treatment and at the end of it for both groups were: T1 group gene expression for NFAT before sessions was $(9.66 \pm 1.17)$ while at the end of sessions was $(11.33 \pm 2.5)$, also in T2 group gene expression was $(16.86 \pm 6.2)$ before chemotherapy treatment, and was $(10.92 \pm 1.49)$ at the end of chemotherapy, as showed in table (5).

\subsection{AP-1 Gene Expression}

Recorded results showed a significant change $(\mathrm{P}>0.05)$ at the gene expression of AP-1 in compared to control group (1.88 \pm 1.25$)$ in T1 group, but it was no significant difference before started sessions $(10.55 \pm 2.5)$ and at the end of sessions $(7.57 \pm 1.81)$, for T2 group the results showed no significant difference in NFAT gene expressions compared to control (1.88 \pm 1.25$)$, also no significant changes before treatment which was (4.53 \pm 1.5$)$ and at the end of treatment was $(3.77 \pm 1.4)$, as showed in table (6).

\subsection{Phototherapy Results}

Results showed remarkable differences between $\mathrm{T} 1$ group patients who are subjected to phototherapy sessions, and T2 group patients who are received chemotherapy treatment, as showed in the table (7, 8). The data showed that the percentage of response and improvement in (T1) group (92\%) at the end of phototherapy sessions (one month later) higher than in (T2) group (60\%) who relied on anti-viral only (one a month later). As well as the results showed that beyond three months later than the started of treatment which the improvement rate in $\mathrm{T} 1$ group was (100\%) complete recovery compared with the $\mathrm{T} 2$ group which was $(80 \%)$.

\subsection{Verbal Pain Scale (VRS)}

The results of the pain scale in patients with HZ, in the T1 group patient who exposed to phototherapy plus antiviral the irritable pain associated with the infected disappeared at the fastest time after the session's end $(0.041 \pm 0.20)$ compared with the group T2 $(0.48 \pm 0.65)$ and after three months later, the rate of VRS was $(0 \pm 0)$ in T1 group compared with the T2 group which was $(0.2 \pm 0.4)$, as showed in the figure (6 and 7$)$.

\section{DisCuSSION}

From the obtained results, it was clear that NB-UVB represent a positive effective tool in treated patients with $\mathrm{HZ}$ and PHN. The recovery from HZ infection was $100 \%$ in patients who subjected NBUVB session and which never developed to PHN in all cases as mentioned in the study of (Jalali et al., 2006) when they used the broad band ultraviolet rays in treatment. The current study also showed the role of NB-UVB in reduction the nerve pain in people living with PHN, as reported in the study of (Eman, 2011). In study of (Knappe 2013) showed that light rays can effect on the nerve ending in the superficial dermises and epidermis by reducing the cutaneous nerve density, in addition light rays have ability to improve the damage nerve ending by regeneration ending damage. NB-UVB also play fundamental role as antimicrobial by inhibiting the replication of viruses through the light rays which can penetrate skin and raised the levels of vitamin $\mathrm{D}$ which induce human beta defense and microbial peptide II - 37 (Jeremy et al.,2013). Through reactivation of latent VZV from sensory ganglia and transport to the skin which followed by skin lesion formation, inflammatory response formed include immune mediators that associated with the release of paracrine secretion such as complement, interferon, histamine, substance p, and pro-inflammatory cytokines (Young,2015). In current results it's clear that pro-inflammatory IL-6 expression was unregulated in patients with acute HZ and PHN and this is come in conformity with previous studies that found IL-6 increment in acute phase of HZ and PHN which influence directly on the nerve ending by destruction these ends, and this situation lead to neurological and also lead to developed the HZ infection to PHN (Guptarak et al.,2013). So it's obvious that NB-UVB had useful effect in down regulation the expression of IL-6 in order to prevent the excessive inflammatory response and to prevent the chronicity of infection, and that was clear from the obtained results between T1 group which had reduction in IL-6 levels at the end of 
phototherapy sessions and T2 group who had significant increment in the IL-6 levels at the end of chemotherapy treatment, as come in the results of (Hong, 2015) . which used UVB plus electro acupuncture and observe the reduction of IL-6 at the end of sessions. The collected results showed that no significant changes in the gene expression of NFAT and AP-1 before starting treatment and at the end of treatment for both T1 and T2 groups, several earlier studies differs among in their results about the effect of activated transcription factors and the role of their gene expression on the TH1 cells (CD4, CD8 lymphocytes) during the infection of HZ some of studies reported that TH1 cells decreased and it is assumed the $\mathrm{HZ}$ incidence, while other studies mentioned the opposite (Sheng et al.,2009). In both conditions increasing or reduction has no association with the development of HZ to PHN (Malayige \& Gathsauric, 2007). But it may associated with viral load and the role of both of CD4 and CD8 T cells mediate viral clearance during acute illness (Gwela,2013). Which may approve that excessive inflammatory responses come from the mediator immune response for damage of infected nerve and not from the T lymphocytes mediator against the virus? In this study the use of NB-UVB to regulate the excessive inflammatory immune responses by induced T-regulatory cells and FOXP3 which consider the key of T- regulatory cells (Elis et al., 2014). That was clear from the obtained results which showed a highly significant elevation in the gene expression of FOXP3 for T1 group at the end of phototherapy sessions compared with chemotherapy group. FOXP3 have ability to expressed anti-inflammatory cytokines such as IL-10 which have crucial role in modulation the role of pro-inflammatory cytokines like IL-2, IL- 6 , and IL-12 by regulate or suppress it, which in turn leads to decrease the inflammation in nerve and prevent the development of $\mathrm{HZ}$ infection to PHN.

Table1. Primer Sequences

\begin{tabular}{|c|c|c|c|}
\hline Primer & \multicolumn{2}{|c|}{ Sequence } & Reference \\
\hline \multirow{2}{*}{$\begin{array}{c}\text { NFAT } \\
\text { Gene }\end{array}$} & $\mathrm{F}$ & GT TGGGGAGT TGGCACTAGC & \multirow{2}{*}{ In this study } \\
\cline { 2 - 3 } AP1 & $\mathrm{R}$ & GACCCGGGCT T TCTACTGG & \multirow{2}{*}{ In this study } \\
Gene & $\mathrm{F}$ & GGTGGGATAAGACCCCCTCA & \multirow{2}{*}{ In this study } \\
\cline { 2 - 3 } FoxP3 & $\mathrm{R}$ & TCCTGCCTGCATAGCAATAGG & \\
\hline Geng & $\mathrm{F}$ & TGTGCTAGGGCGGTATGAGA & (Hayase et al., 2005) \\
\cline { 2 - 3 } GAPDH & $\mathrm{R}$ & GCTGGGGTGCAACTATGGG & \\
\cline { 2 - 3 } & $\mathrm{R}$ & ACGACCACTTTCTCAAGCTC & \\
\hline
\end{tabular}

Table2. Thermo Cycler Protocol

\begin{tabular}{|c|c|c|c|}
\hline qPCR step & Temperature & Time & Repeat cycle \\
\hline Initial Denaturation & $50^{\circ} \mathrm{C}$ & $1 \mathrm{hour}$ & \multirow{2}{*}{45} \\
\hline Denaturation & $95^{\circ} \mathrm{C}$ & $20 \mathrm{sec}$ & \\
\hline $\begin{array}{c}\text { AnnealinglExtension } \\
\text { Detection(scan) }\end{array}$ & $60^{\circ} \mathrm{C}$ & $30 \mathrm{sec}$ & 1 \\
\hline Melting & $60-95^{\circ} \mathrm{C}$ & $0.5 \mathrm{sec}$ & 1 \\
\hline
\end{tabular}

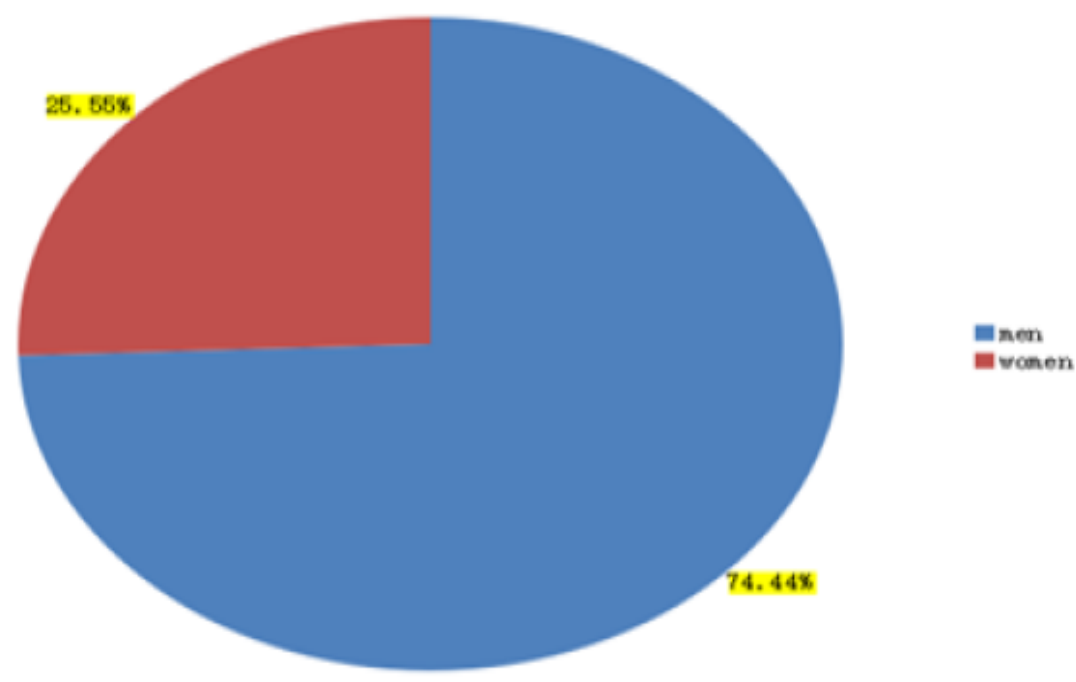

Figure1. Distribution of patients with $H Z$ and PHN by (gender) 


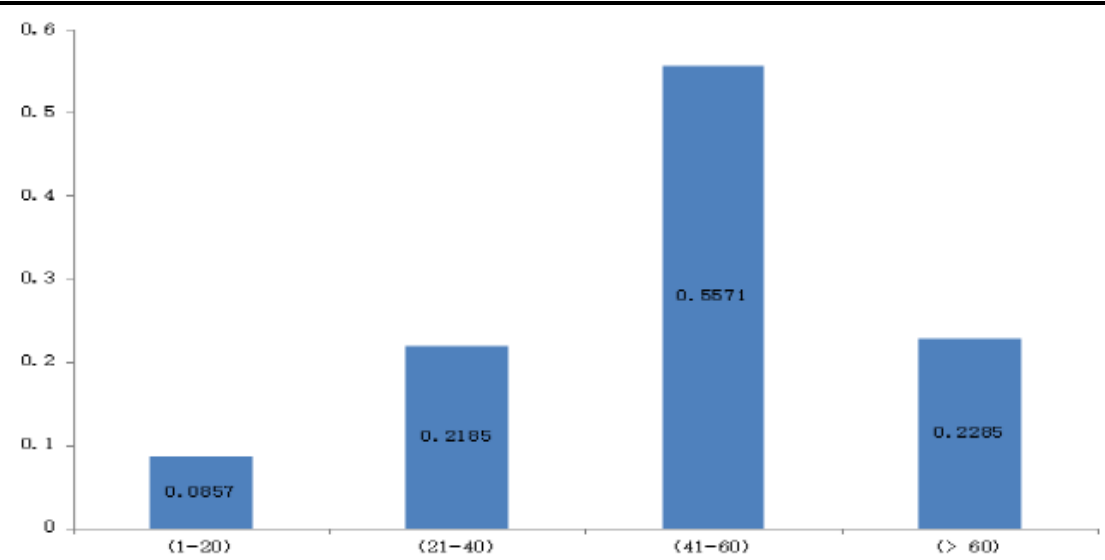

Figure2. Distribution of patients with herpes zoster by age group

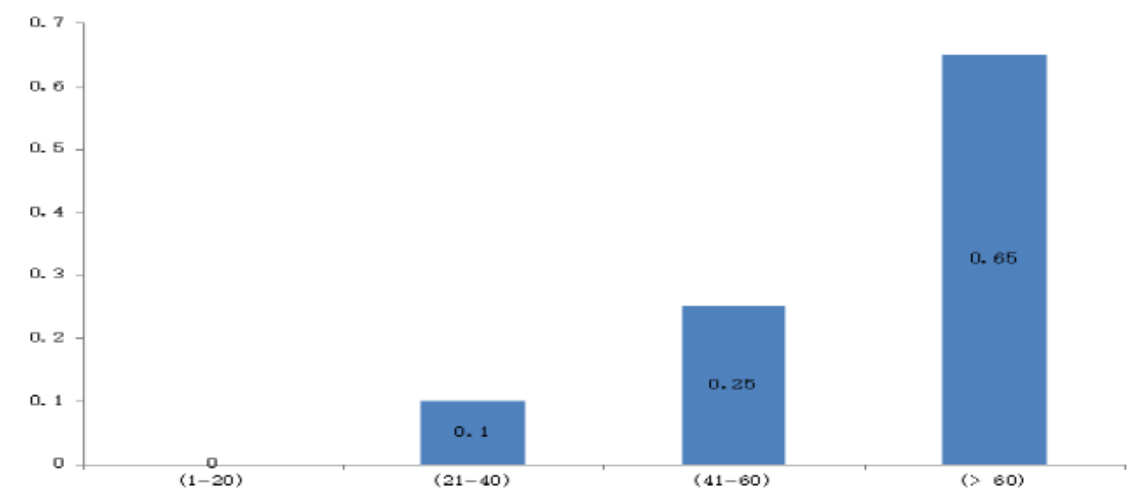

Figure3. Distribution of patients with PHN by age group

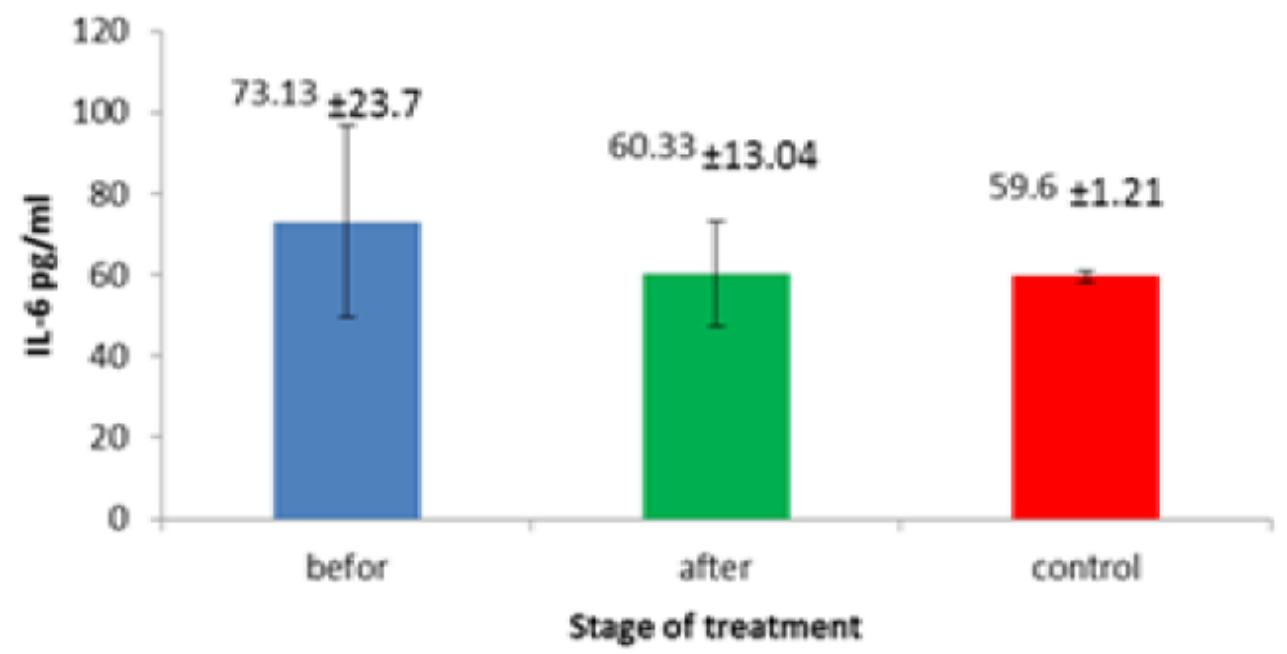

Figure4. Levels of IL-6 at T1 group and control

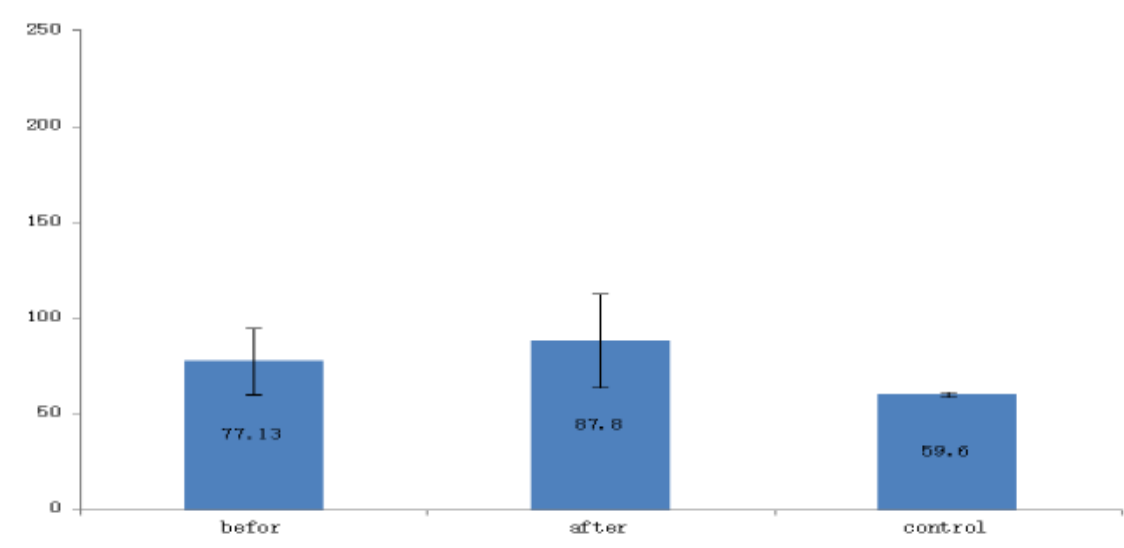

Figure5. Levels of IL-6 at T2 group and control 
Immune Modulation in Patient with Varicella Zoster Virus Treated with Phototherapy and Chemotherapy

Table3. gene expression of FOXP3 by $R T$-qPCR

\begin{tabular}{|c|l|c|c|}
\hline \multirow{2}{*}{ Tretment type } & \multicolumn{3}{|c|}{ Stage of treatment } \\
\cline { 2 - 4 } & Before treatment & At mid period of treatment & At the end of treatment \\
\hline Phototherapy & $10.55 \pm 2.51$ & $9.60 \pm 3.25$ & $18.22 \pm 5.44$ \\
\hline Chemotherapy & $14.55 \pm 10.64$ & $7.89 \pm 5.82$ & $10.85 \pm 6.56$ \\
\hline Control & $1.91 \pm 1.25$ & $1.91 \pm 1.25$ & $1.91 \pm 1.25$ \\
\hline
\end{tabular}

Table4. gene expression of NFAT by RT-qPCR

\begin{tabular}{|c|c|c|c|}
\hline \multirow{2}{*}{ Tretment type } & \multicolumn{3}{|c|}{ Stage of treatment } \\
\cline { 2 - 4 } & Before treatment & At mid period of treatment & At the end of treatment \\
\hline Phototherapy & $9.66 \pm 1.17$ & $8.93 \pm 1.31$ & $11.33 \pm 2.55$ \\
\hline Chemotherapy & $7.66 \pm 3.27$ & $6.50 \pm 1.91$ & $10.92 \pm 1.49$ \\
\hline Control & $3.002 \pm 0.86$ & $3.002 \pm 0.86$ & $3.002 \pm 0.86$ \\
\hline
\end{tabular}

Table5. AP-1 gene expression by RT-qPCR

\begin{tabular}{|l|l|l|l|}
\hline \multirow{2}{*}{ Tretment type } & \multicolumn{3}{|c|}{ Stage of treatment } \\
\cline { 2 - 4 } & \multicolumn{1}{|c|}{ Before treatment } & At mid period of treatment & At the end of treatment \\
\hline Phototherapy & $10.55 \pm 2.516$ & $9.60 \pm 9.60$ & $7.57 \pm 1.81$ \\
\hline Chemotherapy & $4.53 \pm 1.53$ & $5.34 \pm 1.08$ & $3.77 \pm 1.47$ \\
\hline Control & $1.88 \pm 1.25$ & $1.88 \pm 1.25$ & $1.88 \pm 1.25$ \\
\hline
\end{tabular}

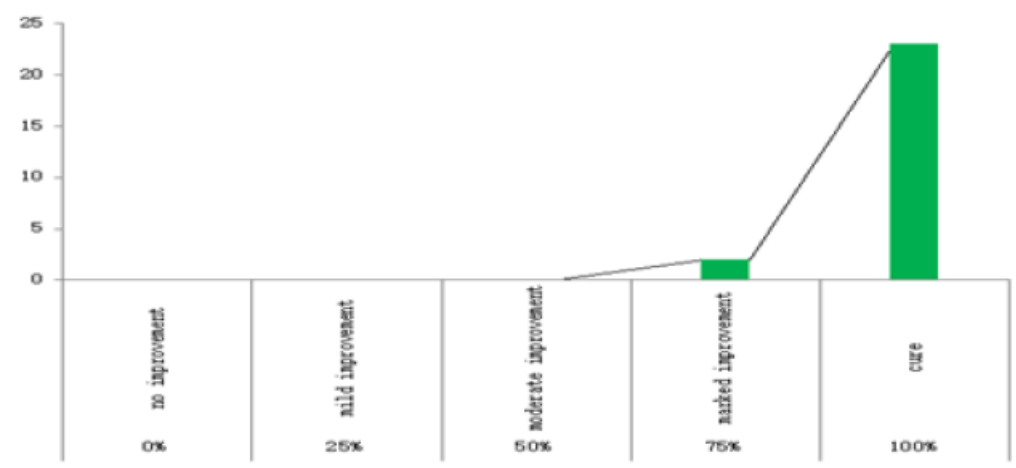

Figure6. Percentages of the degree of improvement in VRS at T1 group befor sessions.

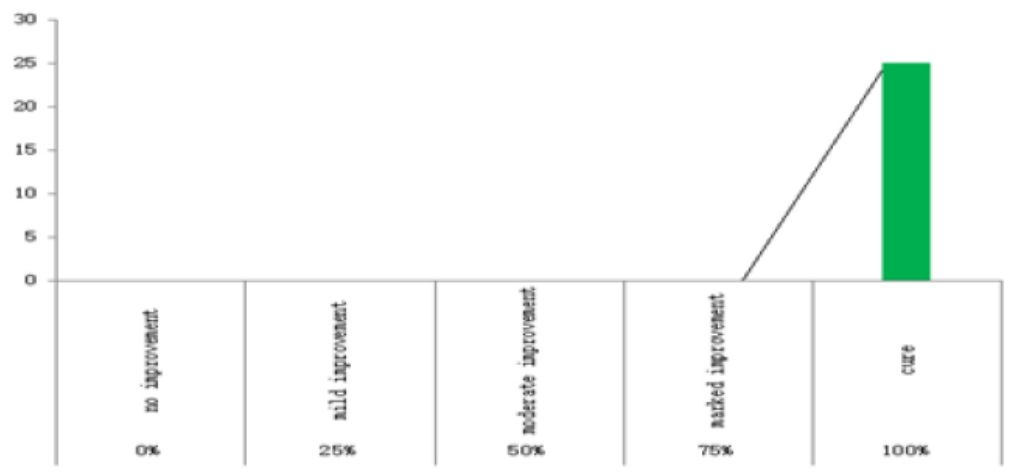

Figure7. Percentage of the degree of improvement in VRS inT1group after three months later

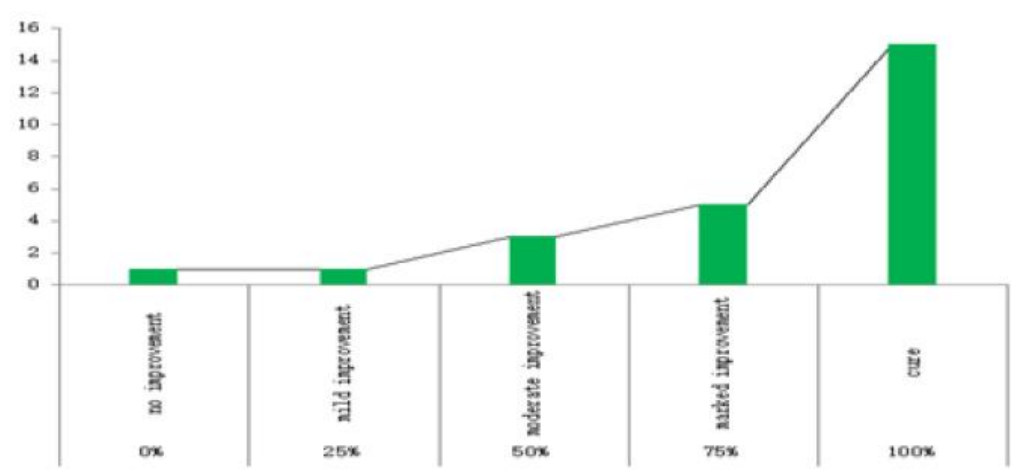

Figure8. Percentage of the degree of improvement in VRS inT2group at the end of chemotherapy 


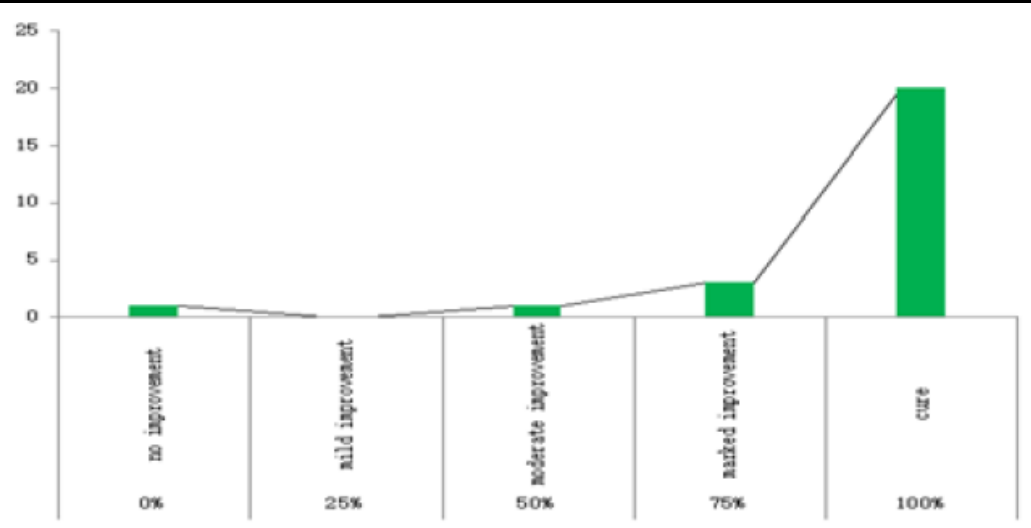

Figure9. Percentage of the degree of improvement in VRS inT2group after three months later

\section{REFERENCES}

[1] Aaron Arvey, Van der Veeken, Robert M Samstein, Yongqiong Feng, John A Stamatoyannopoulos, and Alexander Y R udensky.( 2010). Inflammation-induced repression of chromatin boundy by the transcription factor FOXP3 in regulatory T cells. Nature Immunology 2010., 15:580-587.

[2] Avin AM, Arvin AM, Gilden D.( 2013) VZV. In: Knipe DM, Howley PM, eds. Fields Virology, 5th Edition. Philadelphia, PA: Lippincott Williams \& Wilkins

[3] Elis SD, Mc Govern JL,VanMaurikA,Howe D, EhrensteinMR,Notly CA.( 2014). “ Induced $\mathrm{CD} 8+\mathrm{FOXP} 3+\mathrm{T}$ reg cells in rheumatoid arthritis are modulated by 38 phosophrylation and monocytes expressing membrane tumor necrosis factor $\alpha$ and CD86." Arthritis Rheumatol., 66(1): 2694-705

[4] Eman EL-Nabarawy. (2011).The use of narrow band ultraviolet light B in the prevention and treatment of postherpetic neuralgia (A pilot study).Indian J Dermatol.,56:44-7.

[5] Fernando macian.( 2005).NFAT proteins: key regulators of T-cell development and function . Natural Review of Immunology.,5:472-484.

[6] Gilden D.(2011). Efficacy of life zoster vaccine in preventing zoster and postherpetic neuralgia. Journal of internal medicine.,269(5):496-506.

[7] Guptarak, J., Wanchoo, S., Durham-Lee, J., Wu, Y., Zivadinovic, D., Paulucci-Holthauzen, A., et al. (2013).Inhibition of IL-6 signaling: a novel therapeutic approach to treating spinal cord injury pain. Pain., 154: 1115-1128.

[8] Gwela, Agnes A.( 2013). Analysis of the immune evasion mechanisms of varicella zoster virus, University of oxford.

[9] Haykal K.A, and Desgroseilliers J.P. (2006).Are narrow - band ultraviolet B home unit aviable option for continuous or maintenance therapy of photoresponsive skin disease? Journal of Cutaneous Medicine \& Surgery ., 10(5): 234-240.

[10] Hong Zhang, Xiaodan Xu, Jiao Xang, Yuan Jian.( 2015).Impacts of electroacupuncture combined with ultraviolet therapy on cytokins of herpes zoster at the acute stage in patients . Zhangguo Zhen Jin., 35(2):145-8.

[11] Jalali MHA, Ansarin H, Soltani-Arabshahi R.( 2006). Broad-band ultraviolet B phototherapy in zoster patients may reduce the incidence and severity of postherpetic neuralgia. Photodermatol Photoimmunol and Photomed.,22:232-7.

[12] Jeremy A.Beard,Allison Bearden ,and Rob Striker. (2011).Vitamin D and the anti-viral state .J ClinVirol.,50(3):194-200.

[13] Kaplan M, Kaplan E, Hammerman C et al . (2006). Postphototherapy neonatal billrubin rebound : a potential cause of significant hyperbilirubinaemia . Arch Dis Child., 91: 31-34.

[14] Karolin DE Bosscher, IIse M.Beck, Lien Dejoge, Nadia Bougar, Anthoula Gaigeaux, Sebastien Chateauvieux, Dariusz Ratman, Marc Bracke, Jan Tavernier, Win Vanden Berghe, Chude Libert, Marc Diederich, Guy Haegeman.( 2014). Selective modulation of glucocorticoid receptor can distinguish between transrepression of NF-KB and AP-1. Cellular and Molecular life sciences., 71:134-163. 
[15] Knapp,Daniel J.DC. (2013).Postherpetic Neuralgia: Case Study of Class 4 Laser Therapy Intrvention .Clinical Journal of Pain .,29(10):6-9.

[16] Lewis S.M., Bgin B.J., and Bates A. Daci and Lewis practical hematology. $10^{\text {th }}$ ed. Churchill Livingston. USA 2006; 1-5.

[17] Malavige., Gathsauric Neelika.( 2007). Investigation of Varicella Zoster Virus glycoproteinspecific $\mathrm{T}$ cell responses, University of oxford.

[18] McDonald,J.H.Handbook of Biological statistics, $2^{\text {nd }}$ rd., sparky publishing, Baltimor, Maryland;2009.

[19] Michael N, Ox man. MD.( 2009). Herpes zoster pathogenesis and cell-mediated immunity and immuno seuescence. Journal of the American Osteopathic Association, 109:13-17.

[20] Nagamoto Combs K, Combs CK.( 2010). Microglial phenotype is regulated by activity of transcription factor, NFAT (nuclear factor of activated T cells). J Neurosci., 30(28): 9641-6.

[21] Radonic A, Thulkes S, Mackay IM, Landt O, Siegert W, Nistche A. (2004).Guide line for reference gene selection for quantitative real-time pcr . Biochem Biophys Res Commun., 313:856-862.

[22] Rishi Vishal Luckheeram, Rui Zhou, Asha Devi Verma and Bing Xia . (2012).CD4 T cells: Differentiation and Function. Clinical and Developmental Immunology., ID 925135,12 pages.

[23] Sakaguchi S, M.M,Costantino CM , Hafler DA. (2010).FOXP3+ regulatory T cells in the human immune system .Nature Reviews, 10:490-500.

[24] Sheng-meizhu,Young-min Liu,Er-dan AN and Qing-lian Chen. (2009).Influence of systemic immune and cytokine responses during the acute phase of zoster on the development of postherpetic neuralgia. J Zhejiang UnivSci B., 10(8): 625-630

[25] van Besouw NM, Verjans GM, Zuijderwijk JM, Litjens NH, Osterhaus AD and Weimar W.( 2012). Systemic varicella zoster virus reactive effector memory T-cells impaired in the elderly and in kidney transplant recipients. J Med Virol., 84:2018-25.

[26] Wang G, and Hardy M.P.( 2004). Development of leyding cells in the insulin-ike growth factor-1 (igf-1) knockout mousce: effects of igf-1 replacement and gonadotropic stimulation. Biol Reprod., 70:632-639.

[27] Younk UK Kim, Xindong Liu, Shinya Tanaka, Dat Quoc Tran, Yeonseak Chung.( 2013).Regulation of germinal center reactions by B and T cells. Antibodie., 2:554-586.

[28] Young HoonJeon. (2015).Herpes Zoster and Postherpetic Neuralgia: Practical Consideration for Prevention and Treatment. Korean J Pain, 28(3): 177-184. 